\title{
Extrachromosomal expression of nat05 gene encoding an alkaline serine protease from Bacillus subtilis N05
}

\author{
Nguyen Thi Anh Thu ${ }^{1,4 \#, ~ N g o ~ T h i ~ T u o n g ~ C h a u ~}{ }^{2 \#, ~ L e ~ V a n ~ T h i e n ~}{ }^{2}$, Nguyen Duc HuY $^{3}$, \\ Nguyen Tran Me KhuE ${ }^{1}$, Nguyen Bao Hung ${ }^{1}$, NGUYen Ngoc LuONG ${ }^{1}$, \\ Le Thi ANH Thu ${ }^{1}$, Nguyen HoAng Loc ${ }^{1 *}$ \\ ${ }^{1}$ Institute of Bioactive Compound, College of Sciences, Hue University, Hue, Vietnam \\ ${ }^{2}$ University of Science, Vietnam National University-Hanoi \\ ${ }^{3}$ Institute of Biotechnology, Hue University, Hue, Vietnam \\ ${ }^{4}$ College of Medicine and Pharmacy, Hue University, Hue, Vietnam \\ ${ }^{\#}$ These authors contributed equally in this paper
}

\begin{abstract}
Nattokinase, the fibrinolytic serine protease, has been shown to be beneficial in preventing strokes caused due to blood clots. Therefore, synthesis of recombinant nattokinase in a host system, which can be both safe for human consumption as well as demonstrate good productivity and amenable to the downstream processing, will have a great socioeconomic significance. A nat05 gene encoding nattokinase - the most important serine protease secreted by the Bacillus subtilis natto - was cloned from $B$. subtilis strain N05 and expressed using pHT43 plasmid in another B. subtilis strain (BD170). Enzymatic assays, as well as sodium dodecyl sulfate-polyacrylamide gel electrophoresis (SDS-PAGE) and zymogram, were employed to assess the efficiency of the production of nattokinase using a relatively novel recombinant DNA technique. Among the five recombinant bacterial clones (R1-R5), R4 was found to secrete high amounts of nattokinase into the culture medium, as evidenced by the total proteolytic enzyme assay, fibrinolytic enzyme assay, SDS-PAGE, and zymogram. A preliminary analysis of the biochemical properties of the crude enzyme showed characteristics that are typical of nattokinase as reported by other studies. Thus, in this study, we were able to successfully produce nattokinase in $B$. subtilis strain (BD170) using recombinant DNA approach. The R4 recombinant clone that was found to secrete nattokinase can be used as a source of recombinant protein that can be further purified for various therapeutic applications, or the strain could be used as a probiotic bacterium in functional foods.
\end{abstract}

Key words: Bacillus subtilis N05, fibrinolytic activity, nattokinase, alkaline serine protease

\section{Introduction}

Proteases cleave peptide bonds of various proteins. They are an important group of enzymes both from the physiological as well as commercial point of view (Maciver et al., 1994). Proteases can be classified into seven broad categories: serine proteases, cysteine proteases, threonine proteases, aspartic proteases, glutamic proteases, metalloproteases, and asparagine peptide lyases (Oda, 2012). In serine proteases (or serine endopeptidases), serine serves as the nucleophilic amino acid at the active site (Hedstrom, 2002) and have various applications, especially in the food-processing industry (He- dayati and Sani, 2016) and as chemotherapeutic agents due to their ability to dissolve fibrin clots formed in the blood (Cho et al., 2004).

Some serine proteases with fibrinolytic activity have been isolated from Catharsius molossus (Ahn et al., 2003 and 2005), Lumbricus rubellus (Cho et al., 2004), Periserrula leucophryna (Koo et al., 2010), Perionyx excavatus (Subathra et al., 2011), Streptomyces (Uesugi et al., 2011), Neanthes japonica (Wang et al., 2011), Euphorbia hirta (Patel et al., 2012), and Lucilia sericata (Van der Plas et al., 2014). Fibrinolytic enzymes (also known as nattokinase) have also been found in a variety

\footnotetext{
* Corresponding author: Institute of Bioactive Compound, College of Sciences, Hue University, Hue, Vietnam; e-mail: nhloc@hueuni.edu.vn
} 
of fermented foods such as Japanese natto, Korean cheonggukjang and doenjang, Indonesian gembus, and Chinese douchi. Bacillus subtilis natto has been found to produce these enzymes, which can directly hydrolyze fibrin in blood clots (Afifah et al., 2014). Moreover, many reports on cloning and expression of genes encoding serine protease from various organisms have been published, such as Bacillus sp. (Takami et al., 1992; Maciver et al., 1994; Schmidt et al., 1995; An et al., 2004; Jeong et al., 2007; Nguyen et al., 2013; Hafeez et al., 2015), Thermoactinomyces sp. HS682 (Tsuchiya et al., 1997), Aquifex pyrophilus (Choi et al., 1999), Grifola frondosa (Islam, 2008), Chaetomium thermophilum (Li and $\mathrm{Li}$, 2009), Thermoascus aurantiacus var. levisporus ( $\mathrm{Li}$ et al., 2011), and Pochoniarubescens and Pochonia chlamydosporia (Larriba et al., 2012). Among the serine proteases that possess therapeutic value, nattokinase has gained immense interest among the researchers. This enzyme has been consumed extensively in the form of fermented soybean in East Asian countries such as Japan, Korea, and China. Furthermore, the in vivo blood clot-dissolving capability of nattokinase has been recognized by Western medicine (Weng et al., 2017). Scientists have also attempted to express the gene encoding this enzyme in various hosts such as Escherichia coli ( $\mathrm{Ni}$ et al., 2016), Bacillus lincheniformis (Cai et al., 2016; Wei et al., 2015), Spodoptera frugiperda (Li et al., 2007), protease-deficient $B$. subtilis strain such as WB800 (Nguyen et al., 2013), and engineered B. subtilis strain (Wang et al., 2014). These hosts have been shown to be able to produce recombinant nattokinase in good quantities and few of them can be directly used in functional food production.

In this study, we aimed to establish a recombinant expression system for nattokinase that is safe for human consumption and has reasonable yield, which could further be improved upon and with a potential for commercialization. Therefore, we selected a prototroph B. subtilis strain (BD170) as the expression host. To avoid complications of engineering genome, we selected the extrachromosomal expression of nattokinase by using pHT43, a plasmid that shows great efficiency in $B$. subtilis. To confirm the successful production of this enzyme, we performed enzymatic assays, SDS-PAGE, zymogram, and some preliminary biochemical characterizations of the culture filtrates from the recombinant strains, with recipient strain being used as the control.

\section{Materials and methods}

\section{Bacterial strain}

Proteolytic bacteria were previously isolated and screened from some traditional fermented soybean foods in Vietnam. Among the isolates, strain N05 (natto5) was chosen and identified as B. subtilis (Nguyen et al., 2015). The strain was cultured in Luria-Bertani (LB) medium (containing $1 \%$ tryptone, $0.5 \%$ yeast extract, and $1 \% \mathrm{NaCl}$ ) and kept at $0-80^{\circ} \mathrm{C}$ for long-term storage. The recipient $B$. subtilis strain $\mathrm{BD} 170\left(\mathrm{ATCC}^{\circledR} 33608^{\mathrm{TM}}\right)$ was supplied by Prof. Seung-Moon Park (Division of Biotechnology, Chonbuk National University, Republic of Korea) and was maintained in LB medium. All cloning work was performed in $E$. coli TOP 10 strain (Invitrogen). Liquid LB medium was used for liquid culture and agar LB $(1.5 \%, \mathrm{w} / \mathrm{v})$ was used for solid culture in all experiments of this study.

\section{Cloning of nat05 gene}

Bacillus subtilis N05 was cultured in $5 \mathrm{ml}$ of LB medium at $37^{\circ} \mathrm{C}$ overnight on the orbital shaker with a speed of $180 \mathrm{rpm}$. Cell biomass was obtained by centrifugation at $10000 \mathrm{rpm}$ for $5 \mathrm{~min}$. Total DNA was extracted based on the cetyltrimethylammonium bromide method as described by Minas et al. (2011).

A putative gene encoding serine protease from B. subtilis N05 was generated by the method of polymerase chain reaction (PCR) using a set of NatF- and NatR-specific primers (Table 1) designed from the coding DNA sequence (CDS) of aprN (accession number in NCBI: KJ174338) from B. subtilis MTCC 7164. PCR components including $40 \mathrm{ng}$ total DNA, $10 \mathrm{pmol}$ of each primer, $10 \mu \mathrm{l} 2 \times$ PCR Master Mix (Fermentas), and $\mathrm{ddH}_{2} \mathrm{O}$ were added to a final volume of $20 \mu \mathrm{l}$. Amplification was performed with an initial denaturation at $95^{\circ} \mathrm{C}$ for $5 \mathrm{~min} ; 30$ cycles of $95^{\circ} \mathrm{C}$ for $30 \mathrm{~s}, 55^{\circ} \mathrm{C}$ for $30 \mathrm{~s}$, and $72^{\circ} \mathrm{C}$ for $1 \mathrm{~min}$; and a final extension of $72^{\circ} \mathrm{C}$ for $10 \mathrm{~min}$. The purified amplicon was cloned in $\mathrm{pCR}^{\circledR} 2.1$ vector (Invitrogen) and introduced into $E$. coli TOP10 cells (Invitrogen) by heat-shock method. The recombinant $\mathrm{pCR}^{\circledR} 2.1$ vector was prepared for sequencing the amplicon by the dideoxy chain termination method on the Applied Biosystem 3130 (ABI). After being identified as the gene of interest (named as nat05), the gene was excised from the vector by performing enzymatic digestion using XmaI and BamHI (Thermo Scientific), and 
Table 1. The nucleotide sequences of primers specific for the coding DNA sequence (CDS) of nat05 gene used in the study

\begin{tabular}{c|c}
\hline Name & Nucleotide sequence \\
\hline NatF & $5^{\prime}$-GGATCCTTCAGCAACAAGTCTGC-3' \\
\hline NatR & 5'-CCCGGGTTATTGTGCAGCTGCTT-3' \\
\hline
\end{tabular}

* The bolded sequences are: 5'GGATCC3' - Bam HI recognition site, 5'CCCGGG3' - XmaI recognition site

purified by GeneJET Gel Extraction Kit (Thermo Scientific). Bacillus expression vector, pHT43 (MoBiTec), was also linearized with the same restriction enzymes. Ligation reaction mixture between $\mathrm{pHT} 43$ vector and nat05 was introduced into $E$. coli TOP10 cells by heatshock method (Sambrook et al., 1989).

\section{Expression of nat05 gene}

Transformation of $B$. subtilis BD170 with pHT43/ nat05 vector was performed using chemical transformation as described by Vojcic et al. (2012). The presence of nat05 in the transformed cells was confirmed by colony PCR amplification with specific primers, NatF and NatR.

For expression analysis, recombinant $B$. subtilis BD170 cells containing pHT43/nat05 vector were grown in LB liquid medium on a shaker with a rotation speed of $180 \mathrm{rpm}$ and at $37^{\circ} \mathrm{C}$ for overnight. The culture was then diluted to obtain an optical density reading of 0.15 at $600 \mathrm{~nm}$ using a fresh LB medium. Then, the culture was allowed to grow further until reaching an $\mathrm{OD}_{600}$ value between 0.7 and 0.8 . For the induction of nat05 expression, 1-5 mM isopropyl $\beta$-D-1-thiogalactopyranoside (IPTG) was added in the medium and the mixture was incubated at $37^{\circ} \mathrm{C}$ for $2-10 \mathrm{~h}$. The supernatant containing the extracellular serine protease was harvested after every $2 \mathrm{~h}$.

Expression of nat05 was assayed by sodium dodecyl sulfate $(12 \%, \mathrm{w} / \mathrm{v})$ polyacrylamide gel electrophoresis (SDS-PAGE). The gel was then stained with Coomassie Blue R-250 and the electrophoretic image was analyzed by Quality One software (ver 4.1, BioRad).

\section{Enzymatic activity assays}

The total proteolytic activity of the enzyme was evaluated by loading the culture filtrates of recombinant strains and recipient strain into pre-punched holes of equal sizes on the assay plate containing $1.5 \%$ agar and $2 \%$ skim milk. The plate was then incubated at $37^{\circ} \mathrm{C}$ for
$5 \mathrm{~h}$ and subsequently stained with $0.1 \%$ amido black solution for detection of substrate hydrolysis.

Fibrinolytic activity of the enzyme was determined as described by Deepak et al. (2008). Briefly, the reaction mixture contained $140 \mu \mathrm{l}$ of $50 \mathrm{mM}$ Tris- $\mathrm{HCl}$ and $40 \mu \mathrm{l}$ of $0.72 \%$ fibrinogen (Sigma-Aldrich), which was incubated at $37^{\circ} \mathrm{C}$ for $10 \mathrm{~min}$, followed by the addition of 0.2 unit thrombin (Sigma-Aldrich) and $10 \mu$ of the culture filtrates and were mixed well. The mixture was incubated at $37^{\circ} \mathrm{C}$ for $60 \mathrm{~min}$ and the reaction was terminated by the addition of $200 \mu 10.2 \mathrm{M}$ trichloroacetic acid. The supernatant was recovered by centrifugation at $15000 \mathrm{rpm} / 4^{\circ} \mathrm{C}$ for $5 \mathrm{~min}$ and the fibrinolytic activity in the supernatant was determined at a wavelength of $275 \mathrm{~nm}$. One unit of enzyme activity is defined as the amount of enzyme required to increase the absorbance by 0.01 at $275 \mathrm{~nm}$ after $1 \mathrm{~h}$ incubation.

The fibrinolytic activity of the recombinant enzyme was also estimated by using fibrinogen plate assay. The procedure was similar to the total proteolytic assay described above, but instead of skim milk, we used fibrinogen and thrombin. The culture filtrates of recombinant B. subtilis induced with different amounts of IPTG (1-5 $\mathrm{mM}$ ) were tested against the culture filtrates of recipient strains for fibrin-dissolving ability. Clear zone on the plate is an indicator of the activity of the enzyme.

Fibrin zymogram gel electrophoresis was conducted as described by Choi et al. (2005) with slight modifications. Briefly, the separating gel solution $(12 \%, \mathrm{w} / \mathrm{v})$ was prepared in the presence of fibrinogen $(0.12 \%, \mathrm{w} / \mathrm{v})$ and $100 \mu \mathrm{l}$ of thrombin (10 NIH units/ml). The extracellular enzyme solution was precipitated and washed with cold acetone and redissolved in zymogram sample buffer $(0.1 \mu \mathrm{g} / \mu \mathrm{l})$, which consisted of $0.5 \mathrm{M}$ Tris- $\mathrm{HCl}(\mathrm{pH} 6.8)$, $10 \%$ SDS, $20 \%$ glycerol, and $0.03 \%$ bromophenol blue.

After electrophoresis at $4{ }^{\circ} \mathrm{C}$, the gel was incubated in $50 \mathrm{mM}$ Tris- $\mathrm{HCl}$ buffer ( $\mathrm{pH}$ 7.4) for $30 \mathrm{~min}$ at room temperature on a rotary shaker, which contained $2.5 \%$ Triton X-100. The gel was washed with $\mathrm{ddH}_{2} \mathrm{O}$ for $30 \mathrm{~min}$ to remove Triton X-100 and then incubated in zymogram reaction buffer [ $30 \mathrm{mM}$ Tris- $\mathrm{HCl}(\mathrm{pH} 7.4)$ and $\mathrm{NaN}_{3}$ ] at $37^{\circ} \mathrm{C}$ for $12 \mathrm{~h}$. Then, the gel was stained with Coomassie Blue R-250 for $1 \mathrm{~h}$ to reveal the bands. The bands, corresponding to the areas where fibrin was digested, were visualized as unstained regions of the zymogram gel.

Total protein concentration was determined by the method of Bradford (1976) with bovine serum albumin 
(Sigma-Aldrich) as the standard. The samples were read at a wavelength of $595 \mathrm{~nm}$ against the blank. The specific activity of serine protease was obtained by dividing units of the enzyme with that of the total proteins in the sample.

\section{Effect of metal ions and surfactants}

Metal ions $\left(\mathrm{Ca}^{2+}\right.$ and $\left.\mathrm{Cu}^{2+}\right)$ and surfactants (SDS, Tween 20, and Triton X100) were tested for their effect on the enzymatic activity of nat05. The enzyme was preincubated with $5 \mathrm{mM}$ of the metal ion or $5 \%$ of the surfactant for $10 \mathrm{~min}$ and the remaining activity of the enzyme was then measured as described above.

\section{Statistical analysis}

Each enzymatic assay on the plate was repeated thrice and the averages were compared by one-way ANOVA by Duncan's test at a level of 0.05 using the SPSS program.

\section{Results}

\section{Cloning nat05 gene}

A DNA band (amplicon) in Figure 1 demonstrates the successful PCR amplification of nat05 with a length of approximately $1.1 \mathrm{~kb}$, as predicted. This shows that nat05 from $B$. subtilis N05 was successfully cloned and expressed in B. subtilis BD170.

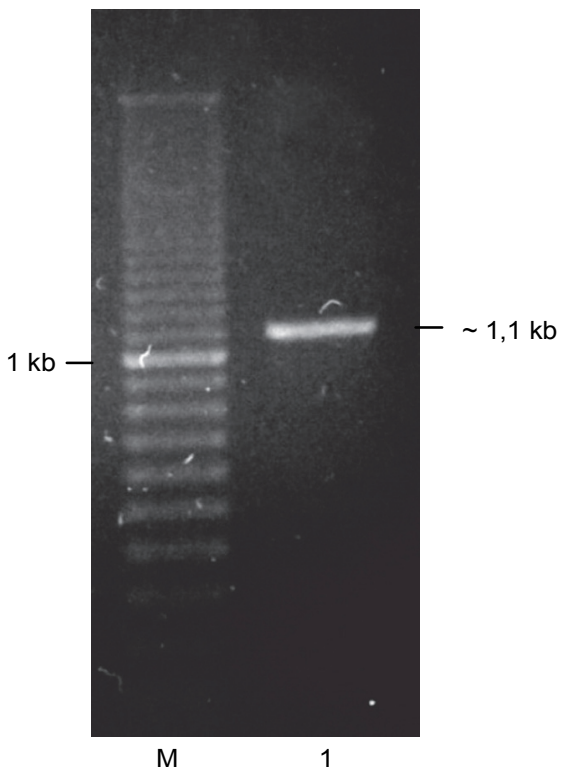

Fig. 1. PCR amplification of total DNA from Bacillus subtilis N05 using specific primers (NatF and NatR); M - DNA electrophoresis size standard (BioRad), 1 - amplicon
BLAST search indicated that the nucleotide sequence of the amplicon (1147 nt) is highly identical (98\%) to the CDS of the aprN. This sequence has been named as nat05 and deposited in NCBI with the accession number of KU341115. Sequence alignment analysis of the deduced amino acid sequences of nat 05 and aprN enzymes indicated that they are $99 \%$ identical. The nat05 was subsequently released from $\mathrm{pCR}^{\circledR} 2.1$ vector with $\mathrm{XmaI}$ and $B a m H I$ and was inserted into the pHT43 vector to be expressed in B. subtilis BD170 cells. This full-length gene also encodes for the peptidase inhibitor I9 (85 amino acids (aa)) as well as the secretory signal peptide (21 aa) that are located on the $\mathrm{N}$-terminal end of the polypeptide chain.

\section{Expression of nat05 gene}

Five colonies (R1-R5) of the transformed B. subtilis BD170 cells from the selective plate (LB agar medium supplemented with chloramphenicol) were randomly selected for the analysis of proteolytic activity. The proteolytic activity of extracellular enzymes from the five colonies was tested on skim milk agar plate. The resulting plate (Fig. 2A) displayed clear zones around holes into which culture filtrates were loaded, indicating the presence of proteases in the culture. Since the amount of culture filtrates loaded on each hole was same, differences in the size of clear zones indicated differences in the amount of protease present in the culture filtrates. The difference between $D$ and $d$ (where $D$ is the diameter of the clear zone from the center and $d$ is the diameter of pre-punched hole for loading enzyme) was used to estimate the amount of protease present in each culture filtrate. R4 recombinant strain secreted the highest amount of protease into the culture medium ( $D-d$ was approximately $16 \mathrm{~mm}$ ). The $D-d$ of $\mathrm{NC} 1$ and $\mathrm{NC} 2$ (culture filtrates from the recipient strain $B$. subtilis BD170) were only about 6 and $5 \mathrm{~mm}$, respectively.

Based on these results, the R4 strain was selected for further estimation of fibrinolytic activity. Figure 2B shows the activity of extracellular serine protease from cultures induced with various concentrations of IPTG. The clear zone of R4 clone showed the highest value of approximately $12 \mathrm{~mm}$ diameter when the expression of nat05 was induced with $4 \mathrm{mM}$ of IPTG for $8 \mathrm{~h}$, whereas $\mathrm{NC} 1$ and $\mathrm{NC} 2$ showed weak activity, with the diameters of the clear zones of about 4 and $2 \mathrm{~mm}$, respectively. 


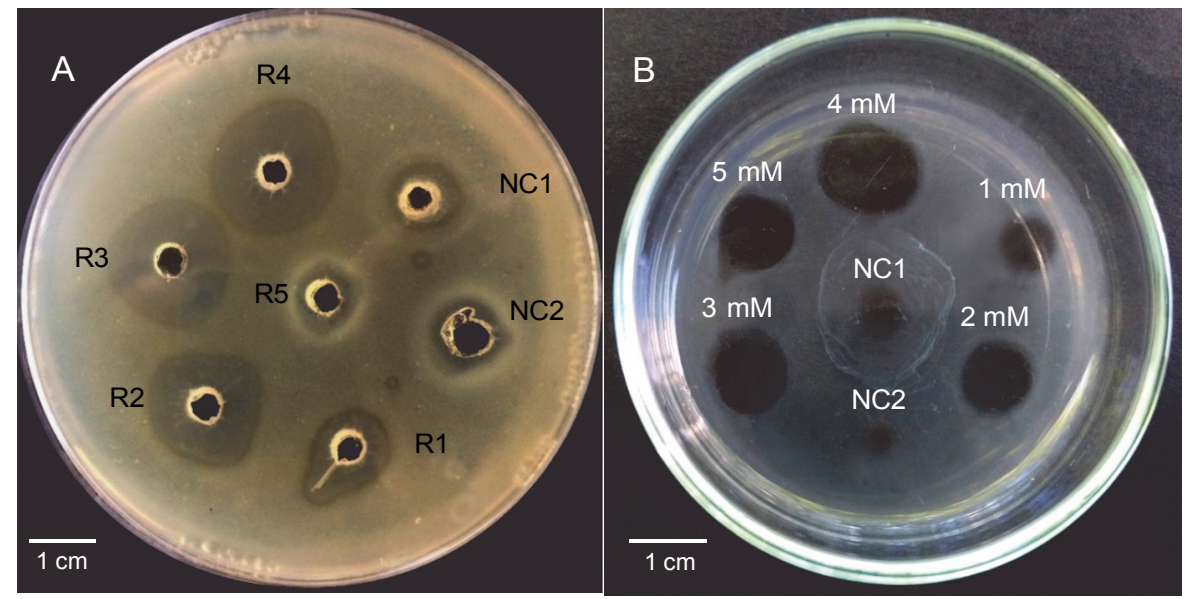

Fig. 2. A) Proteolytic activity of extracellular enzymes from Bacillus subtilis on $2 \%$ skim milk agar plate. R1-R5, culture filtrates from transformed $B$. subtilis BD170 strains induced with $4 \mathrm{mM}$ isopropyl $\beta$-D-1-thiogalactopyranoside (IPTG); NC1 and NC2, culture filtrates from the recipient strain $B$. subtilis BD170. B) Fibrinolytic activity of extracellular enzyme from $B$. subtilis on a fibrinogen plate. $1-5 \mathrm{mM}$, transformed $B$. subtilis BD170 strain (R4) induced with different concentrations of IPTG; NC1 and $\mathrm{NC} 2$, culture filtrates from the recipient strain B. subtilis BD170.

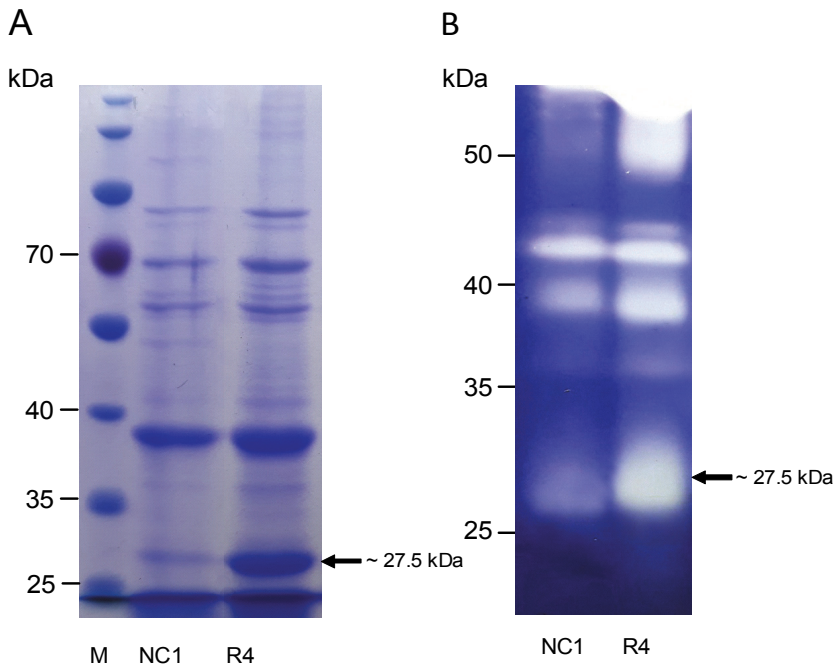

Fig. 3. SDS-PAGE A) and fibrin zymography B) of culture filtrates from recombinant and recipient strains after being concentrated by cold acetone; $\mathrm{M}$ - prestained dual color protein molecular weight marker (MyBioSource), $\mathrm{NC1}$ - Bacillus subtilis $\mathrm{BD} 170$ recipient strain, $\mathrm{R} 4-B$. subtilis $\mathrm{BD} 170$ recombinant strain induced with $4 \mathrm{mM}$ isopropyl $\beta$-D-1-thiogalactopyranoside (IPTG)

SDS-PAGE and zymography analyses revealed, as expected, that nat05 enzyme had a molecular weight of approximately $27.5 \mathrm{kDa}$ (Fig. 3). This result is consistent with the fact that after cleavage and release of peptidase inhibitor and signal peptide, the remaining polypeptide contains 275 aa, which has a molecular weight of approximately $27.5 \mathrm{kDa}$. We cannot, however, rule out the presence of other serine proteases of the same molecular weight in the recombinant strains, as a search of serine proteases in $B$. subtilis with the molecular weight of $27-28 \mathrm{kDa}$ on GenBank yielded at least two more enzymes (phage-like element PBSX, AN P54326.2 and an uncharacterized protein, AN P45920.2).

\section{Preliminary analysis of biochemical properties of the nat05 enzyme}

Although a purified nat05 enzyme is more suitable for the analysis of its biochemical properties, herein, we attempted to characterize the extracellular enzyme filtrate (mixture of nat05 and other possible serine proteases) to obtain information regarding the thrombolytic enzymes produced by the recombinant strain. Our results are in-line with those obtained for the purified nattokinase that has been reported in other studies (Nguyen et al., 2013; Deepak et al., 2008). Figure 4 shows that the thrombolytic enzyme mixture displayed an optimal activity at $\mathrm{pH} 9$ and $37^{\circ} \mathrm{C}$, with the specific activity reaching the highest value of approximately $470 \mathrm{U} / \mathrm{mg}$ protein than that of the control sample of $302 \mathrm{U} / \mathrm{mg}$ protein (recipient strain, wild-type $B$. subtilis BD170). In general, the nat05 enzyme was unstable at acidic conditions but was relatively stable under alkaline conditions (Fig. 4A).

In addition, the fibrinolytic activity of the nat05 enzyme decreased when exposed to ions such as $5 \mathrm{mM}$ calcium (75\%) and $5 \mathrm{mM}$ copper (22\%) or a nonionic deter- 

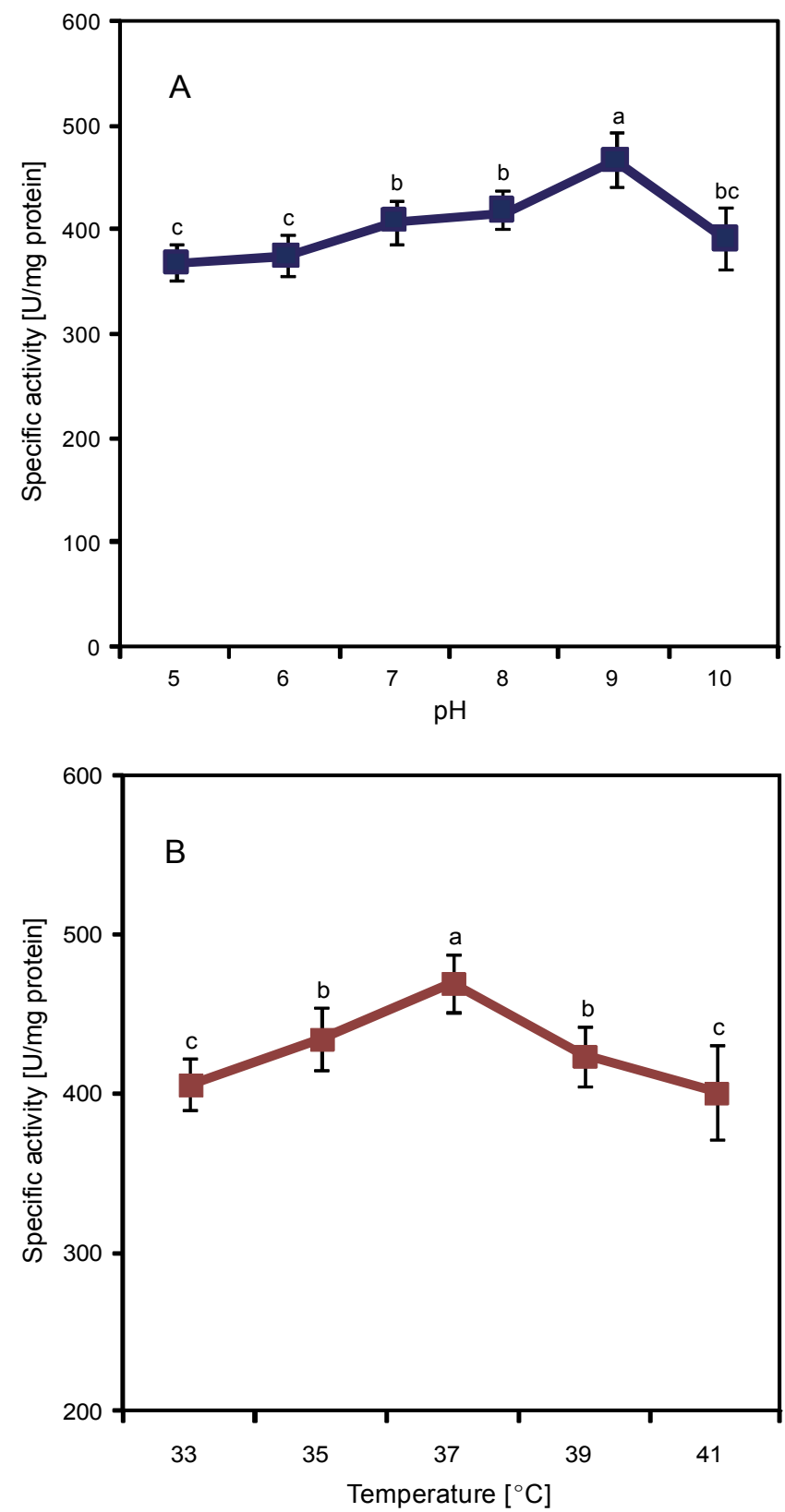

Fig. 4. Effect of $\mathrm{pH} \mathrm{A}$ ) and temperature B) on the fibrinolytic activity of nat05 enzyme. Different letters on the plot indicate significantly different means (Duncan's test, $P<0.05$ )

gent such as $5 \%$ Tween 20 (87\%) but significantly increased when exposed to 5\% Triton X-100 (155\%). Furthermore, 5\% SDS strongly inhibited the activity of nat05 (8\%) (Fig. 5).

\section{Discussion}

In literature, there are many studies published on the genes encoding alkaline serine proteases in Bacillus species. Bacillus species produce enzymes that have

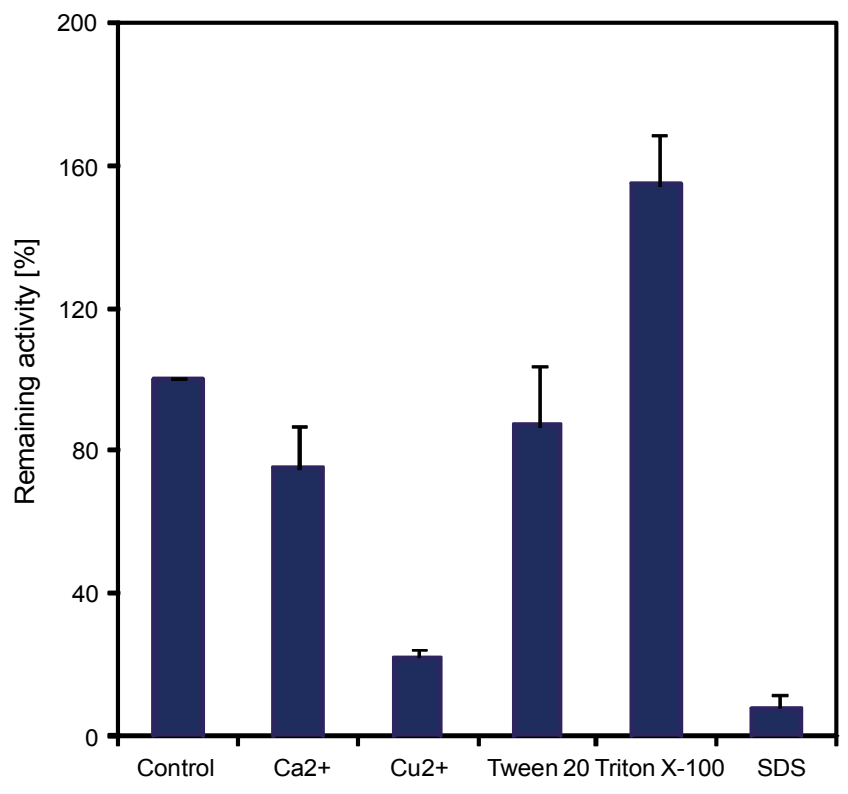

Fig. 5. Effect of ions and nonionic substances on the fibrinolytic activity of nat05 enzyme

various properties and molecular weights (Takami et al., 1992; Maciver et al., 1994; An et al., 2004; Jeong et al., 2007; Sadeghi et al., 2009; Nguyen et al., 2013; Hafeez et al., 2015).

Some of these genes have been successfully expressed in E. coli or B. subtilis and the basic properties of recombinant serine proteases have also been analyzed. For example, the enzyme from Bacillus sp. Ak1 produced in $E$. coli (approximately $36 \mathrm{kDa}$ ) had an optimal $\mathrm{pH}$ and temperature of 8.5 and $75^{\circ} \mathrm{C}$, respectively (Maciver et al., 1994). Hafeez et al. (2015) have obtained a $30.5 \mathrm{kDa}$ serine protease of $B$. subtilis from recombinant $E$. coli cells with an enzyme activity of $6 \mathrm{U} / \mathrm{ml}$. Furthermore, serine proteases originated from Bacillus species have also been expressed in suitable $B$. subtilis strains. For example, Takami et al. (1992) showed that Bacillus sp. 221 protease produced in B. subtilis DB-104 had an optimal temperature of $30-50^{\circ} \mathrm{C}$ (at pH 11) and an optimal $\mathrm{pH}$ of $11.5-12$. However, the enzymatic activity of this protease was not found to be very strong as only small halos were observed around the colonies on the skim milk agar plates. Nguyen et al. (2013) expressed nattokinase gene encoding a pre-pro-protein enzyme including a pre-signal peptide (30 aa), a pro-peptide (76 aa), and a mature protein (275 aa) from $B$. subtilis VTCC-DVN-12-01 in B. subtilis WB800. Nattokinase (a serine protease with fibrinolytic activity) with mole- 
cular weights of $27.7 \mathrm{kDa}$ and $\mathrm{pI} 6.6$ exhibited a specific activity of $12.7 \mathrm{U} / \mathrm{mg}$. An optimum activity of enzyme was observed at $65^{\circ} \mathrm{C}$ and $\mathrm{pH} 9$, and it was also stable at $50^{\circ} \mathrm{C}$ and in a wide range of $\mathrm{pH}$ values (from 5 to 11 ). Jeong et al. (2007) found the fibrinolytic activity of an enzyme which originated from $B$. subtilis $\mathrm{CH} 3-5$ in protease-deficient $B$. subtilis strain with a molecular weight of approximately $29 \mathrm{kDa}$. This enzyme exhibited higher activities toward fibrin rather than casein. Except for the study of Jeong et al. (2007), who used fibrinogen as a substrate to determine the fibrinolytic activity, the other studies only determined the proteolytic activity using skim milk (Takami et al., 1992) and casein (Hafeez et al., 2015) or the amidolytic activity with succinyl-AlaAla-Pro-Phe-p-nitroanilide as a substrate (Nguyen et al., 2013). Maciver et al. (1994) did not determine the activity of serine proteases.

In this study, the nat05 enzyme from $\mathrm{R} 4$ clone showed some properties that were relatively different from the above-mentioned serine proteases such as the molecular weight of approximately $27.5 \mathrm{kDa}$ with the highest fibrinolytic activity of about $470 \mathrm{U} / \mathrm{mg}$ protein at $\mathrm{pH} 9$ and $37^{\circ} \mathrm{C}$. Moreover, the enzyme was found to be inhibited by certain metal ions $\left(\mathrm{Ca}^{2+}\right.$ and $\left.\mathrm{Cu}^{2+}\right)$ and surfactants (Tween 20 and SDS), especially, SDS strongly affected the enzymatic activity. However, Triton X-100 was found to increase the fibrinolytic activity of nat 05 by up to $155 \%$. Nguyen et al. (2013) also found that metal ions (e.g., $\mathrm{Ca}^{2+}, \mathrm{Cu}^{2+}, \mathrm{Mn}^{2+}$, and $\mathrm{Zn}^{2+}$ ) inhibited the activity of nattokinase from $B$. subtilis VTCC-DVN-12-01; however, EDTA and $\mathrm{Mg}^{2+}$ increased the activity significantly.

Although we did not purify or directly detect this enzyme in this study, based on the total proteolytic and fibrinolytic enzyme assays, as well as SDS-PAGE and zymogram results of the culture filtrates of the recombinant strain compared with the recipient strain, we can safely conclude that nat05 has been successfully expressed as secretory enzyme in the $B$. subtilis BD170 strain. In addition to the evidence from enzymatic assays, SDSPAGE, and zymogram images, our preliminary biochemical characterization of the crude mixture of the enzyme in the culture filtrate also showed typical properties of a nattokinase (Nguyen et al., 2013; Deepak et al., 2008).

\section{Conclusions}

In this study, we have successfully cloned and expressed nat05 encoding a full-length fibrinolytic enzyme, nattokinase, from $B$. subtilis N05 strain in a prototroph host $B$. subtilis BD170. Preliminary analysis of the expression and biochemical characterization of the culture filtrates from the selected recombinant strains showed that the enzyme was secreted into the culture media with full activity. To the best of our knowledge, this is the first report on plasmid expression of the fibrinolytic serine protease from $B$. subtilis in a prototroph $B$. subtilis strain.

\section{Acknowledgments}

This work was supported by the Ministry of Industry and Trade (Grant number: ĐT.04.15/CNSHCB).

\section{Conflicts of interest}

All authors have declared that there have been no conflicts of interest.

\section{Contributors}

Loc N.H. designed the study and wrote the manuscript. Thu N.T.A., Chau N.T.T., Thien L.V., Huy N.D., Khue N.T.M., Hung N.B., Luong N.N., and Thu L.T.A performed the experiments and managed literature searches. Loc N.H., Thu N.T.A., and Chau N.T.T. analyzed data. All the authors read and approved the final manuscript.

\section{Ethical approval}

Not required.

\section{References}

Afifah D.N., Sulchan M., Syah D., Yanti, Suhartono M.T., Kim J.H. (2014) Purification and characterization of a fibrinolytic enzyme from Bacillus pumilus 2.g isolated from Gembus, an Indonesian fermented food. Prev. Nutr. Food Sci. 19(3): 213-219.

Ahn M.Y., Hahn B.S., Ryu K.S., Hwang J.S., Kim Y.S. (2003) Purification and characterization of a serine protease with fibrinolytic activity from the dung beetles, Catharsius molossus. Thromb. Res. 112(5-6): 339-347.

Ahn M.Y., Hahn B.S., Ryu K.S., Hwang J.S., Kim Y.S. (2005) Purification and characterization of a serine protease (CPM-2) with fibrinolytic activity from the dung beetles. Arch. Pharm. Res. 28(7): 816-822.

An S.Y., Ok M., Kim J.Y., Jang M.S., Cho Y.S., Choi Y.L., Kim C.H., Lee Y.C. (2004) Cloning, high-level expression and enzymatic properties of an intracellular serine protease from Bacillus sp. WRD-2. Indian J. Biochem. Biophys. 41: 141-147.

Bradford M.M. (1976) A rapid and sensitive method for quantitation of microgram quantities of protein utilizing the principle of protein-dye-binding. Anal. Biochem. 72(1-2): 248-254.

Cai D., Wei X., Qiu Y., Chen Y., Chen J., Wen Z., Chen S. (2016) High-level expression of nattokinase in Bacillus lin- 
cheniformis by manipulation signal peptide and signal peptidase. J. Appl. Microbiol. 121(3):704-12.

Cho I.H., Choi E.S., Lim H.G., Lee H.H. (2004) Purification and characterization of six fibrinolytic serine-proteases from earthworm Lumbricus rubellus. J. Biochem. Mol. Biol. 37(2): 199-205.

Choi I.D., Bang W.G., Kim S.H., Yu Y.G. (1999) Extremely thermostable serine-type protease from Aquifex pyrophilus-molecular cloning, expression, and characterization. J. Biol. Chem. 274(2): 881-888.

Choi N.S., Yoo K.H., Hahm J.H., Yoon K.S., Chang K.T., Hyun B.H., Maeng P.J., Kim S.H. (2005) Purification and characterization of a new peptidase, bacillopeptidase DJ-2, having fibrinolytic activity: Produced by Bacillus sp. DJ-2 from Doen-Jang. J. Microbiol. Biotechnol. 15(1): 72-79.

Deepak V., Kalishwaralal K., Ramkumarpandian S., Babu S.V., Senthilkumar S.R., Sangiliyandi G. (2008) Optimization of media composition for nattokinase production by Bacillus subtilis using response surface methodology. Bioresour. Technol. 99(17): 8170-8174.

Hafeez Z., Mukhtar H., Gohar U.F., Haq I.U. (2015) Cloning and expression of serine alkaline protease from a locally isolated Bacillus subtilis. Int. J. Biol. Biotech. 12(3): 347-353.

Hedayati G., Sani A.M. (2016) Application of melon serine protease in food processes. Biotechnol. Ind. J. 12(1): $18-24$.

Hedstrom L. (2002) Serine protease mechanism and specificity. Chem. Rev. 102(12): 4501-4524.

Hwang K.J., Choi K.H., Kim M.J., Park C.S., Cha J. (2007) Purification and characterization of a new fibrinolytic enzyme of Bacillus licheniformis KJ-31, isolated from Korean traditional Jeot-gal. J. Microbiol. Biotechnol. 17(9): 1469-1476.

Islam M.M. (2008) Molecular cloning, expression and characterization of a serine proteinase from Japanese edible mushroom, Grifola frondosa: solving the structure-function anomaly of a reported aminopeptidase. Electron. J. Biotechnol. DOI: 10.2225/vol11-issue4-fulltext-5.

Jeong S.J., Kwon G.H., Chun J., Kim J.S., Park C.S., Kwon D.Y., Kim J.H. (2007) Cloning of fibrinolytic enzyme gene from Bacillus subtilis isolated from Cheonggukjang and its expression in protease-deficient Bacillus subtilis strains. J. Microbiol. Biotechnol. 17(6): 1018-1023.

Koo K.B., Suh H.J., Ra K.S., Kim Y.H., Joo H.S., Choi J.W. (2010) Fibrinolytic activity of a novel serine protease from the hemolymph of a polychaeta, Periserrula leucophryna. J. Korean Soc. Appl. Biol. Chem. 53(2): 149-157.

Larriba E., Martin-Nieto J., Lopez-Llorca L.V. (2012) Gene cloning, molecular modeling, and phylogenetics of serine protease P32 and serine carboxypeptidase SCP1 from nematophagous fungi Pochonia rubescens and Pochonia chlamydosporia. Can. J. Microbiol. 58(7): 815-827.

Li A.N., Li D.C. (2009) Cloning, expression and characterization of the serine protease gene from Chaetomium thermophilum. J. Appl. Microbiol. 106(2): 369-380.
Li A.N., Xie C., Zhang J., Zhang J., Li D.C. (2011) Cloning, expression, and characterization of serine protease from thermophilic fungus Thermoascus aurantiacus var. levisporus. J. Microbiol. 49(1): 121-129.

Li X., Wang X., Xiong S., Zhang J., Cai L., Yang Y. (2007) Expression and purification of recombinant nattokinase in Spodoptera frugiperda cells. Biotechnol. Lett. 29(10): 1459-1464.

Maciver B., McHale R.H., Saul D.J., Bergquist P.L. (1994) Cloning and sequencing of a serine proteinase gene from a thermophilic Bacillus species and its expression in Escherichia coli. Appl. Environ. Microbiol. 60(11): 3981-3988.

Minas K., McEwan N.R., Newbold C.J., Scott K.P. (2011) Optimization of a high-throughput CTAB-based protocol for the extraction of $q P C R$-grade DNA from rumen fluid, plant and bacterial pure cultures. FEMS Microbiol. Lett. 325(2): 162-169.

Nguyen D.H., Nguyen Q.A., Ferreira R.C., Ferreira L.C., Tran L.T., Schumann W. (2005) Construction of plasmid-based expression vectors for Bacillus subtilis exhihiting full structural stability. Plasmid, 54(3): 241-248.

Nguyen T.T., Quyen T.D., Le H.T. (2013) Cloning and enhancing production of a detergent- and organic-solvent-resistant nattokinase from Bacillus subtilis VTCC-DVN-12-01 by using an eight-protease-gene-deficient Bacillus subtilis WB800. Microbial Cell Factories, 12: 79.

Nguyen V.T.H., Chau N.T.T., Nhue N.P., My L.T.P., Tuyen H. (2015) Classification and assessment of nattokinase biosynthesis of the strain bacillus subtilisnatto 5 isolated from fermented soybean. Vietnam J. Biotechnol. 2: 275-282.

Ni H., Guo P.C., Jiang W.L., Fan X.M., Luo X.Y., Li H.H. (2016) Expression of nattokinase in Escherichia coli and renaturation of its inclusion body. J. Biotechnol. 10(231): 65-71.

Oda K. (2012) New families of carboxyl peptidases: serinecarboxyl peptidases and glutamic peptidases. J. Biochem. 151(1): 13-25.

Patel G.K., Kawale A.A., Sharma A.K. (2012) Purification and physicochemical characterization of a serine protease with fibrinolytic activity from latex of a medicinal herb $E u$ phorbia hirta. Plant Physiol. Biochem. 52: 104-111.

Sadeghi H.M.M., Rabbani M., Naghitorabi M. (2009) Cloning of alkaline protease gene from Bacillus subtilis 168. Res. Pharm. Sci. 4(1): 43-46.

Sambrook J., Fritsch E.F., Maniatis T. (1989) Molecular Cloning: A Laboratory Manual. 2nd ed. Cold Spring Harbor Laboratory Press, Cold Spring Harbor, NY.

Schmidt B.F., Woodhouse L., Adams R.M., Ward T., Mainzer S.E., Lad P.J. (1995) Alkalophilic Bacillus sp. strain LG12 has a series of serine protease genes. Appl. Environ. Microbiol. 61(12): 4490-4493.

Subathra S., Sultana M., GnanamaniM. (2011) Fibrinolytic activity of serine protease of Perionyx excavatus. J. Biosci. Res. 2: 38-45.

Takami H., Kobayashi T., Kobayashi M., Yamamoto M., Nakamura S., Aono R., Horikoshi K. (1992) Molecular cloning, nucleotide sequence, and expression of the struc- 
tural gene for alkaline serine protease from alkaliphilic Bacillus sp. 221. Biosci. Biotechnol. Biochem. 56(9): 1455-1460.

Tsuchiya K., Ikeda F., Tsuchiya T., Kimura T. (1997) Cloning and expression of an intracellular alkaline protease gene from alkalophilic Thermoactinomyces sp. HS682. Biosci. Biotechnol. Biochem. 61(2): 298-303.

Uesugi Y., Usuki H., Iwabuchi M., Hatanaka T. (2011) Highly potent fibrinolytic serine protease from Streptomyces. Enzyme Microb. Technol. 48(1): 7-12.

Van der Plas M.J.A., Andersen A.S., Nazir S., van Tilburg N.H., Oestergaard P.R., Krogfelt K.A., van Dissel J.T., Hensbergen P.J., Bertina R.M., Nibbering P.H. (2014) A novel serine protease secreted by medicinal maggots enhances plasminogen activator-induced fibrinolysis. PLoS One 9(3): e92096.

Vojcic L., Despotovic D., Martinez R., Maurer K.H., Schwaneberg U. (2012) An efficient transformation method for Bacillus subtilis DB104. Appl. Microbiol. Biotechnol. 94(2): 487-493.
Wang S., Deng Z., Li Q., Ge X., Bo Q., Liu J., Cui J., Jiang X., Liu J., Zhang L., Hong M. (2011) A novel alkaline serine protease with fibrinolytic activity from the polychaete, Neanthes japonica. Comp. Biochem. Physiol. B. Biochem. Mol. Biol. 159(1): 18-25.

Wang Y., Chen Z., Zhao R., Jin T., Zhang X., Chen X. (2014). Deleting multiple lytic genes enhances biomass yield and production of recombinant proteins by Bacillus subtilis. Microb. Cell Fact.13: 129.

Wei X., Zhou Y., Chen J., Cai D., Wang D., Qi G., Chen S. (2015) Efficient expression of nattokinase in Bacillus lincheniformis: host strain construction and signal peptide optimization. J. Ind. Microbiol. Biotechnol. 42(2): 287-95.

Weng Y., Yao J., Sparks S., Wang K.Y. (2017) Nattokinase: an oral antithrombotic agent for the prevention of cardiovascular disease. Int. J. Mol. Sci. 18(3). Pii:E523. 